\title{
User Experience of Video-on-Demand Applications for smart TVs: A Case Study
}

\author{
Linda Miesler, Bettina Gehring, Frank Hannich, and Adrian Wüthrich \\ ZHAW Zurich University of Applied Sciences, Institute of Marketing Management, \\ Switzerland \\ linda.miesler@zhaw.ch
}

\begin{abstract}
The convergence of internet and TV and its consequences on TV producers as well as TV users has been a highly discussed topic over the past few years. With the rapid growth of high-speed broadband connections and the development of high-performance TVs, the foundation for the creation and proliferation of smarter TVs enabling the user with a more personalized viewing experience was laid. As a consequence, new business opportunities have opened up and new players have entered the market. Facing a rapidly changing environment with hardly any standards established yet, the consideration of customer satisfaction and user experience plays a major role. Especially in the entertainment industry, user experience is of high relevance and user-centered design an important precondition for service adoption. Therefore, the case study below investigated success factors and barriers which influence usage of a video-on-demand application for smart TVs. Based on a case study of a European video-on-demand service different usability evaluation methods had been applied and combined in order to evaluate and enhance platform performance.
\end{abstract}

Keywords: smart TV, Video-on-demand, User experience, Usability evaluation procedure, Closed loop.

\section{Introduction}

As a result of the increasing convergence of internet and TV, smart TVs are gaining popularity around the world, reshaping existing media usage patterns [1].

According to the definition of Shin, Hwang and Choo [2], a smart TV is a television set with integrated internet capabilities. Similar to smart phones, smart TVs allow users an increased control over content and timing and to choose from a more diverse range of content and applications such as video-on-demand [3].

However, a big variety of offerings as well as new market entrants have increased competition and made it difficult for the individual provider to succeed. Before adopting new applications and services, users must recognize their added value compared to existing services [4], which underlines the relevance of the concept of user experience [5] [6] [7].

The research at hand is based on a case study done in collaboration with a cloudbased video-on-demand service provider for the European market. The company was 
founded in 2006 and is part of an international media corporation. They hold multinational license agreements with movie studios in Hollywood and Europe.

The video-on-demand service is offered via various end devices; the main focus, however, is on smart TV apps. The service is pre-installed on the smart TVs of all leading manufacturer brands, which represents an important competitive advantage for the company. It was a key goal of the provider to offer a unique experience to viewers ("Select a movie with a few clicks").

Although the initial position looked promising, the service provider faced the following challenges:

- Demand for the service was low. Only $1.08 \%$ of buyers of a new smart TV made use of the service. Of these, only $22.1 \%$ were paying customers. The reasons behind the restrained usage were not clear.

- There was a high market risk due to various alternative possibilities for the consumption of video-on-demand on smart TVs (e.g. digital TV of telecommunication providers and cable operators via set-top box, Apple TV etc.) and new players entering the market.

In order to be able to defend their current position and to establish video-ondemand via smart TV apps as standard for movie consumption, it was extremely important for the service to better understand the motives behind the limited use of the service. The present study was conducted for this reason. The specific objectives for the research were the following:

- Identifying and eliminating usage barriers based on an in-depth understanding of user needs, expectations and media consumption behavior

- Establishing an internal control process (closed loop) as a basis for developing and optimizing the service offering

- Helping to increase conversion (with regard to registration and purchases) and consumption rate (with regard to the amount spent per user) for the service as primary goals

Besides the specific goals which were formulated based on the app provider's problems, we further aimed at developing an integrated and generalizable usability evaluation procedure to gain in-depth knowledge about actual user behavior by analyzing existing and newly collected information.

\section{Literature Review of Success Factors in smart TV (Application) Adoption and Usage}

In order to identify success factors of smart TV applications and smart TVs in general, we conducted a literature review of existing studies. Not surprisingly, 
research on the adoption and usage of smart TV applications and its success factors is still scarce (as pointed out recently by Shin, Hwang, \& Choo [2] or Ko, Chang \& Chu [3]). Ko, Chang \& Chu [3] distinguished between 21 functions for digital TV application services and found that apps like video-on-demand had the largest direct effect on the users' intention to adopt digital TV application services However, exactly what determines if users adopt and use such services is still an open question.

A few authors already investigated factors that drive the adoption of smart TVs in general [1] [2]. Lee [1] identified six key constructs deduced from several innovation adoption models (e.g., technology acceptance model (TAM), diffusion of innovation theory (DIT)) such as perceived usefulness / perceived ease of use, and perceived risk. However, due to the abstract manner of such concepts it was difficult to derive insights for our specific use case. Concepts like perceived usefulness strongly emphasize the user's utilitarian motives for smart TV adoption and usage. As a matter of fact, as the main goal of watching television is entertainment and relaxation [8], a smart TV also has to fulfil these hedonic user needs. In line with this, Shin, Hwang \& Choo [2] formulated the challenge facing the smart TV industry as designing services that are "useful, valuable, enjoyable and, most importantly, user-centred". Their results suggested that usability is not the only important factor for technology adoption, but that utility and hedonism are also important. Hedonism can be fulfilled by both; content and interactive services. Therefore, smart TVs and their applications can be described as convergence of task-oriented and entertainment-oriented technology [2] [4]; the interplay of both creates the "user experience". Firms should not only create products and services which are easy to use, but deliver emotional experiences in order to create value for customers and differentiate from competitors [9]. In the field of entertainment services for mobile devices, Kim, Kim \& Kil [4] pointed out the importance of intrinsic motivation for adoption of mobile entertainment services. Zhou [10] also examined the effect of flow experience on user adoption of mobile TV.

To sum up, it was possible to identify four insights from the literature: First, for the adoption and usage of video-on-demand as a specific smart TV application, we differentiate user experience from the technical usability concept. That means, we assumed that not only "effectiveness, efficiency and satisfaction" (cf., definition of ISO [11]) drive adoption and usage, but that user experience as a whole, including its functional and hedonic perspective, needs to be considered. Second, in contrast to existing usability studies that concentrate on user perceptions as determinants of smart TV adoption [1] [2], it was important that the present study focused on actual usage behavior. Third, existing studies mostly focus on the smart TV itself [4] [3], whereas we accentuated our research on one specific application of the smart TV (video-ondemand). Fourth, conclusions from existing studies should be treated with caution since most studies used Korean samples. It is important to remember that the European market does not behave in the same way like the Korean market. Korean consumers are more familiar with innovative technologies than European consumers due to technological advantage of Asian countries. 


\section{Usability Evaluation Procedure}

There are different methodologies regarding usability and user experience evaluation which have proven effective. However, considering the multi-dimensionality of the usability construct, a multi-faceted approach seemed most appropriate. As has been shown, a combination of well-established methods allows the identification of usability problems from different perspectives and leads to better results than adopting only one single method. In addition, each method is capable of identifying usability problems that the other does not, therefore emphasizing the complementary value of the different evaluation methods [12].

Thus, a standard usability evaluation procedure for smart TV applications has been developed by combining several prevalent methods for usability evaluation in order to assess platform usability of the service (Fig. 1). To be able to compare the data collected with different methods, a user's typical "viewing journey" (i.e., registration for the service, searching, buying and watching a movie) was used as an underlying framework.

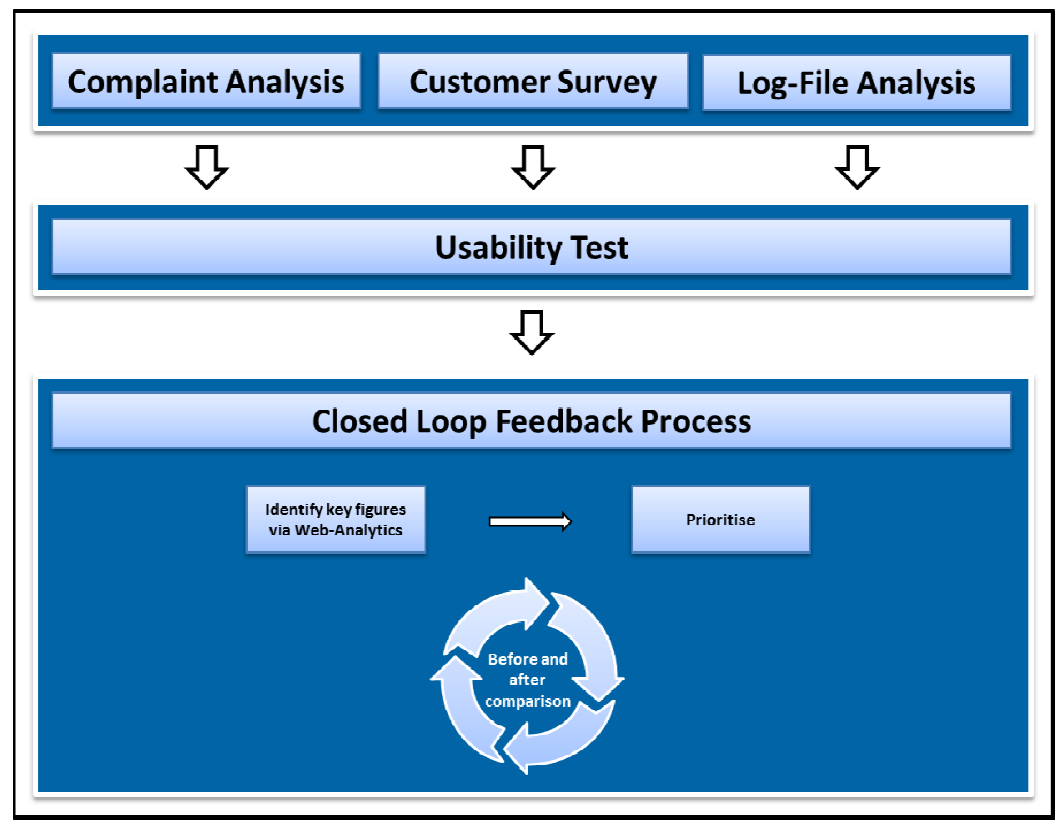

Fig. 1. Usability evaluation procedure

\subsection{Service and Complaint Analysis}

The assessment of service and complaint requests gives direct indications for difficulties occurring during the usage process. By evaluating service and complaint requests, general areas of concern can be identified which serve as inputs for further analysis. 
In the context of the study, existing user complaints and service requests were analyzed to develop preliminary assumptions about factors which might be detrimental for service adoption. A sample $(n=256)$ of service and complaint requests accrued between May and October 2012 was categorized according to six content categories (registration, new movie releases, movie search, payment, play movie, language) including 15 sub-categories. The categorization gave an indication of major problems users were facing when using the service and provides the basic structure ("viewing journey") for subsequent steps.

It must be taken into consideration, however, that normally only paying customers and users with major problems complain; the others do not take the effort. Furthermore, of the users who are dissatisfied with the service generally only $20-30 \%$ complain [13]. This implies that service and complaint analysis is suitable for identifying urgent problems but less for revealing more subtle usability issues.

\subsection{Online Survey}

In a second step, an online survey was carried out in order to gain a better understanding of user characteristics and their media usage behavior. Registered users were surveyed via an online questionnaire $(n=3$ '224) which consisted of 57 items, covering media consumption behavior in general as well as perception of and satisfaction with the specific service. The users' characteristics identified by the survey were used subsequently to define the selection criteria for the participants of the usability test.

\subsection{Software-Based Usability Evaluation Methods (Web Analytics)}

Software-based usability evaluation methods or web analytics use software tools to measure service usage and identify usability problems. It involves collecting, measuring, analyzing, monitoring and reporting web usage data to understand users' behavior [12] [14].

In the case study at hand, log file data from the smart TV app was analyzed during a period of six months in order to find out how users navigate through the service and where breaches in the usage process arise. As data from previous periods was analyzed as well, a server-based log file analysis tool was chosen. Server-based log file techniques record the clicks of each user on the website. A log file is an electronic record of all request activities at a website that updates each time a request (hit) is made from a computer terminal. When a file is requested from a website, its server records the request and enters it into a log file on the server [12] [14].

The data collection process was twofold: First, the data was gathered on an aggregated level by linking the platform to an open source analysis tool. This allowed generating different web metrics (e.g. average time on site, average page views per visit) to measure platform usage and performance. Second, on an individual level, clickstream data was evaluated using approximating techniques. Most frequent user 
pathways were visualized with the purpose to illustrate users' click behavior and identify deviations from ideal paths. To suit firm-specific specifications, a special tool was developed which generated various reports based on the available log files.

In the usability evaluation procedure, log file analysis was used as a means of giving direction for the subsequent usability test by quickly indicating general usability problems or specific problem pages. By means of the log file analysis, the findings from preceding steps could be quantitatively supported and critical barriers in the usage process be drawn out.

\subsection{Usability Test}

Based on the preliminary evidence from step 1, in a laboratory usability test potential usage barriers and drivers were analyzed more deeply. Participants were selected based on criteria in accordance with results from the online survey on a typcial user (e.g., age range 30-50 years; moderate level of technical expertise). Sixteen participants without experience with the application were asked to verbalize their thoughts and feelings while solving eight scenarios (i.e., think aloud). The scenarios covered the full range of the viewing experience (e.g., registering for the service, browsing through movies). The test was accompanied by pre- and post-test interviews for further insights (e.g., expectation of video-on-demand service, semantic associations, and subjective satisfaction with usage experience).

\section{Discussion of Main Results and Closed Loop Process}

\subsection{Results of the Case Study}

The results of the online survey confirmed preliminary assumptions that the market for video on demand service is highly competitive and the commitment from users to a specific application low. They also emphasized the need for the service in question to design the user experience in accordance with user needs and to deliver a unique experience.

In the context of the service and complaint analysis, user requests were categorized along the viewing journey. Major areas of concern in the usage process turned out to be the login / registration as well as the payment process (e.g., problems with double movie bookings due to delayed remote feedback). Further problems were buffering and playback issues.

The log file analysis provided valuable evidence where breaches in the usage process arose and allowed to quantify their impact. Fig. 2 shows a landscape of the aggregated clickstream data for the video-on-demand service clustered according to the three main processes in the viewing journey 'searching', 'watching' and 'buying'. The ovals symbolize the different pages of the application; the numbers displayed represent the number of clicks on that specific page. The linkages between the boxes show the "jumps" between the pages, indicating the number of users that have taken a particular path. In total, there were 50 jumps of 10'000 different IP addresses. Users 
with more than 200 clicks were excluded as these most likely were system requests from computers.

Of particular interest were how many users entered the application, how many of them moved from "searching" to "watching" to "buying" as well as determining which stage saw the highest percentage of exits. The results of the analysis showed that first-time visitors are mostly stuck within the searching stage (82.9\% of all clicks) and do not advance to the purchase stage. Thus, the majority of exits happen within the search process.

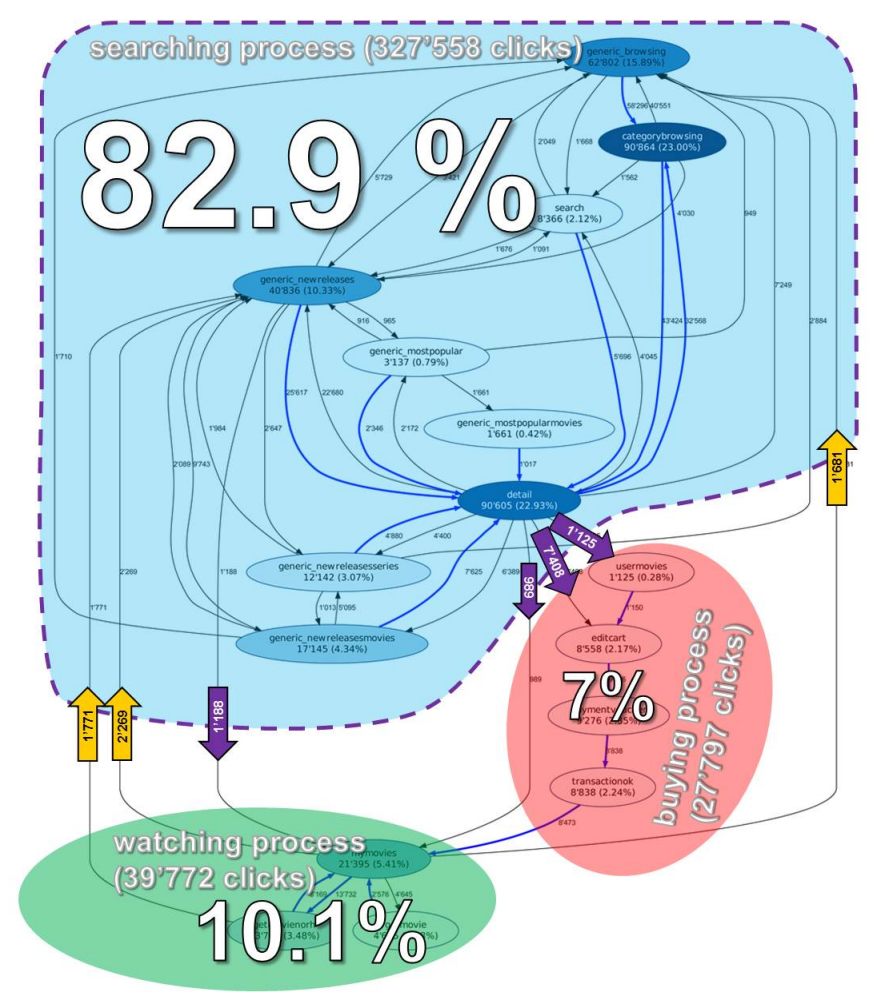

Fig. 2. Clickstream landscape

The usability test revealed some interesting findings on factors impairing the user's viewing experience. General findings were that inconsistent and incorrect wording as well as technical language both influenced user experience negatively. The navigation via remote control was perceived as difficult and was a reason for drop outs. Inconsistent interaction design and information architecture confused users and provoked unnecessary click rates, also impairing user experience.

In terms of the viewing journey mainly two parts of the "journey" stood out negatively during the usability testing. First, during the registration for the application, the interaction between the app and user via remote control impaired customer 
experience. For example, the response time of the application was very slow and the feedback was delayed after input via remote control, so the user perceived the interaction to be tiresome. Second, during the search phase, the text input via remote control was again a potential usage barrier. The inconsistent interaction design confused the user and resulted in unnecessary clicks: for instance, two buttons/fields were labelled "Back", but they differed in their functions (if user pushes the "wrong" back button, search results were lost). As emotions aroused by interaction with the application are an important component of a positive user experience, we analyzed "think aloud" protocols specifically with regard to emotional statements and categorized the statements as positive or negative emotional expressions. Three fifths of the identified emotional statements had a negative valence. Especially during the registration, negative emotions were elicited. Negative emotions were related to remote control, waiting times and navigation.

\subsection{Closed Loop Control Process and Web Metrics}

Based on the findings from steps 1 and 2, a concept for a closed loop optimization process was developed. For this reason, relevant key figures which reflect user experience quality and which can be extracted from log files (e.g., average page views per visit, percentage of exits during movie search, conversion rate) were identified and prioritized in order to establish a comprehensive in-house feedback system (Table 1). This serves as a starting point for the implementation of a continuous measurement and control process which allows the provider to evaluate the user interface systematically and to adapt it according to user requirements.

Table 1. Web metrics

\begin{tabular}{|c|c|c|}
\hline \multicolumn{3}{|l|}{ General Metrics } \\
\hline Indicator & Formula & Description \\
\hline Average time on site/app & & $\begin{array}{l}\text { Measures how long a user } \\
\text { spends time on the app. } \\
\text { Time is a good indicator } \\
\text { for website efficiency. } \\
\text { The goal is not necessari- } \\
\text { ly to reduce time to a } \\
\text { minimum, but to optimize } \\
\text { website architecture and } \\
\text { navigation for a positive } \\
\text { user experience. }\end{array}$ \\
\hline Average page views & & $\begin{array}{l}\text { By measuring the average } \\
\text { views of a specific page, } \\
\text { changes can be tracked } \\
\text { over time and irregulari- } \\
\text { ties identified. }\end{array}$ \\
\hline
\end{tabular}


(Table 1. Continued.)

\begin{tabular}{|c|c|c|}
\hline \multirow[t]{2}{*}{ Clickthrough rate (CTR) } & $\begin{array}{l}\text { number of clicks to a } \\
\text { page }\end{array}$ & \multirow[b]{2}{*}{$\begin{array}{l}\text { By measuring the average } \\
\text { clicks to a specific page } \\
\text { within the same process } \\
\text { (e.g. watching process), it } \\
\text { is possible to compare } \\
\text { metrics over time and } \\
\text { derive improvement } \\
\text { measures (e.g. double } \\
\text { clicks leading to double } \\
\text { bookings in the payment } \\
\text { process due to delayed } \\
\text { remote feedback). }\end{array}$} \\
\hline & $\begin{array}{l}\text { number of views per } \\
\text { process }\end{array}$ & \\
\hline Jumps & & $\begin{array}{l}\text { Number of clicks } \\
\text { ("jumps") from one } \\
\text { process into the next. }\end{array}$ \\
\hline Site exits per process & & $\begin{array}{l}\text { Counting the number of } \\
\text { exits in total for a specific } \\
\text { process (searching } \\
\text { process, buying process, } \\
\text { watching process). } \\
\text { Exit points may indi- } \\
\text { cate weaknesses in the } \\
\text { usage process which } \\
\text { should be tackled. }\end{array}$ \\
\hline $\begin{array}{l}\text { Percentage of high, me- } \\
\text { dium and low frequency } \\
\text { visitors }\end{array}$ & & $\begin{array}{l}\text { Indicates how often a } \\
\text { user returns to the site. } \\
\text { User behavior and de- } \\
\text { rived metrics can be ana- } \\
\text { lyzed with regard to } \\
\text { group differences (e.g. } \\
\text { single or returning visi- } \\
\text { tors). }\end{array}$ \\
\hline \multicolumn{3}{|l|}{ Specific Metrics } \\
\hline Indicator & Formula & Description \\
\hline $\begin{array}{l}\text { Conversion rate } \\
\text { (registration) }\end{array}$ & $\begin{array}{l}\text { number of registered us- } \\
\text { ers }\end{array}$ & $\begin{array}{l}\text { Measures how many } \\
\text { users successfully register } \\
\text { for the application. }\end{array}$ \\
\hline $\begin{array}{l}\text { Conversion rate } \\
\text { (purchase) }\end{array}$ & $\begin{array}{c}\text { number of purchases } \\
\text { number of registered us- } \\
\text { ers }\end{array}$ & $\begin{array}{l}\text { Measures the number of } \\
\text { successful purchases } \\
\text { compared to the number } \\
\text { of registrations. }\end{array}$ \\
\hline $\begin{array}{l}\text { Consumption rate } \\
\text { (average order value) }\end{array}$ & $\varnothing$ amount spent / user & $\begin{array}{l}\text { Captures the average } \\
\text { amount a user spends } \\
\text { within a certain time } \\
\text { period. }\end{array}$ \\
\hline
\end{tabular}


The specific combination of methods in this case study allows a holistic view of the customer experience and is able to measure the impact on key performance indicators (KPIs). The main problem areas with regard to user experience can be identified via survey and complaint analysis. These also form the basis for customer segmentation. The results can be linked to specific elements and pages of the app by means of the log file analysis and their impact can be quantified. Based on the findings from preliminary stages, the usability test can then be focused on the critical topics in order to gain more in-depth insights into the motivational and emotional aspects of the customer experience which are starting point for further development and optimization of the application. To close the loop, the impact of software changes on web metrics can be measured and controlled live, without time-lag, by web analytics techniques.

\section{Conclusion}

Concluding, by combining qualitative and quantitative methods, it was possible to take the perspective of the user and to optimize the user experience systematically with regard to customer value. While the most common problems in the usage process could be identified via log file analysis, the qualitative analysis delivered the underlying reasons. Based on the assessment of the relevant key figures developed as part of a closed loop feedback process, the service provider can in future quantify and measure the impact of changes in the service on actual user behavior and experience.

\section{References}

1. Lee, S.: A Study on Acceptance and Resistance of smart TVs. International Journal of Contents 8(3), 12-19 (2012)

2. Shin, D.-H., Hwang, Y., Choo, H.: smart TV: are they really smart in interacting with people? Understanding the interactivity of Korean smart TV. Behaviour\& Information Technology 32(2), 156-172 (2013)

3. Ko, H.-T., Chang, C., Chu, N.-S.: An empirical investigation of the consumer demand for digital television application services. Behaviour\& Information Technology 32(4), 397-409 (2013)

4. Kim, K., Kim, G.-M., Kil, E.S.: Measuring the compatibility factors in mobile entertainment service adoption. The Journal of Computer Information Systems 50(1), 141-148 (2009)

5. European Commission, Green Paper - on the online distribution of audiovisual works in the European Union: opportunities and challenges towards a digital single market (July 13, 2011), http: / / ec . europa .eu/internal_market/consultations / docs / 2011 / audiovisual/green_paper_COM2011_427_en.pdf (Febraury15, 2012)

6. Foscht, T., Swoboda, B.: Käuferverhalten: Grundlagen - Perspektiven - Anwendungen, 4th edn. Gabler, Wiesbaden (2011)

7. Scherf, K.: IPTV and the Digital Home. A Parks Associates white paper. Parks Associates, Dallas (2009)

8. Rubin, A.M.: Ritualized and Instrumental Television Viewing. Journal of Communication 34(4), 67-77 (1984) 
9. Pine, B.J., Gilmore, J.H.: Welcome to the experience economy. Harvard Business Review 76(4), 97-106 (1998)

10. Zhou, T.: The effect of flow experience on user adoption of mobile TV. Behaviour\& Information Technology 32(3), 263-272 (2013)

11. ISO, ISO 9241-11, international standard first edition. Ergonomic requirements for office work with visual display terminals (VDTs), part 11: guidance on usability (1998), http://www.it.uu.se/edu/course/homepage/acsd/vt09/ IS09241part11.pdf (August 29, 2012)

12. Hasan, L., Morris, A., Probets, S.: E-commerce websites for developing countries - A usability evaluation framework. Online Information Review 37(2), 231-251 (2013)

13. Schröder, R., Wall, F.: Controlling zwischen Shareholder Value und Stakeholder Value. OldenbourgVerlag, Munich (2009)

14. Wilson, R.D.: Using clickstream data to enhance business-to-business web site performance. Journal of Business \& Industrial Marketing 25(3), 177-187 (2010) 